\title{
An epidemiological study on occupational acute pyrethroid poisoning in cotton farmers
}

\author{
Shuyang Chen, Zuowen Zhang, Fengsheng He, Peipei Yao, Yiqun Wu, Jinxiu Sun, Lihui Liu, \\ Quangui Li
}

\begin{abstract}
A cross sectional survey on the prevalence of acute pyrethroid poisoning in cotton farmers was conducted in 1987 and 1988 . A total of 3113 pyrethroid spraymen (2230 men $(71 \cdot 6 \%)$ and 883 women $(28 \cdot 4 \%)$ ) were interviewed after spraying and followed up for $\mathbf{7 2}$ hours. Adverse effects of pyrethroid exposure were found in 834 of them $(26.8 \%)$ manifested as abnormal facial sensations, dizziness, headache, fatigue, nausea, or loss of appetite. Only 10 subjects, who developed significant systemic symptoms and had signs of listlessness or muscular fasciculation, were diagnosed as having mild occupational acute pyrethroid poisoning with a prevalence of $0.31 \%$ in subjects exposed to pure pyrethroids and $0.38 \%$ in subjects exposed to pyrethroid organophosphate mixtures. Measurements of pyrethroid concentrations in the air of the breathing zone, in skin pads, and in urine samples showed that dermal contamination is the main route of exposure to pyrethroids in cotton growers. Preventive measures are recommended.
\end{abstract}

Pyrethroid insecticides have been used in pest control in China since 1982. Undesirable acute pyrethroid poisonings occurred in cotton growers and 573 cases were reported in Chinese medical publications during 1982-8. ${ }^{1}$ To assess the extent of the problem an epidemiological survey on the prevalence of acute pyrethroid poisoning was conducted on the cotton growers of Gaocheng county, Hebei province. The present article reports the results of this study and makes recommendations for the prevention of acute pyrethroid poisoning in cotton farmers.

Institute of Occupational Medicine, Chinese Academy of Preventive Medicine, 29 Nan wei Road, Beijing, People's Republic of China

S Chen, Z Zhang, F He, P Yao, Y Wu, L Liu, Q Li

Institute of Occupational Health of Hebei Province, Shijiashung, Hebei, People's Republic of China J Sun
Subjects, methods, and results

STUDY POPULATION

Eight villages in Gaocheng county with 3390 families and a population of 19692 were selected as clusters for sampling. No appreciable differences existed in farming techniques, types of pyrethroid insecticides applied, styles of spraying, and living standards between the villages selected and the other areas in Gaocheng county. For the present analyses, 16579 subjects were excluded because they were not eligible, including those who had never used any pesticide (for example, children) or those who had not sprayed pyrethroids during the period of June to August in 1987 and 1988 or who used pyrethroids mixed with organophosphates in 1988; also excluded were families who did not grow cotton. Based on these criteria, 3144 subjects from 3053 families were selected for this study. Thirty one $(1 \%)$ subjects lost in the follow up survey were then excluded. Eventually 3113 subjects participated; $2230(71 \cdot 6 \%)$ were men and $883(28.4 \%)$ were women. The average age was $31 \cdot 8$ (range $15-72$ ), most $(57 \cdot 4 \%$ ) being between 25 and 44 . Most $(77.8 \%)$ had been educated in primary and secondary schools.

A cross sectional survey was conducted from June to August in 1987 and 1988. The procedures established by the World Health Organisation ${ }^{2}$ on field surveys of exposure to pesticide were followed. A pilot study was also conducted and a structured questionnaire was administered. To ensure standardisation and quality of the collected data, training of all field staff in appropriate data collection techniques was provided before the survey, and completed questionnaires were checked mutually by the project personnel every day. Information on demographic factors, exposure to pyrethroids or other pesticides, medical history, and possible causal factors of acute pyrethroid poisoning were obtained by the questionnaire from the studied subjects during a follow up for 72 hours.

\section{EXPOSURE ASSESSMENT}

\section{Atmospheric temperature}

During the period of survey, the atmospheric temperature was $25-33^{\circ} \mathrm{C} ; 74 \%$ of the spraymen had 
Table 1 Exposure of spraymen to pyrethroids in 1987 and 1988

\begin{tabular}{|c|c|c|c|}
\hline \multirow[b]{2}{*}{ Pesticides } & \multicolumn{3}{|c|}{ No of subjects } \\
\hline & 1987 & 1988 & Total $(\%)$ \\
\hline $\begin{array}{l}\text { Deltamethrin: } \\
\text { Pure EC } \\
\text { Mixed with organophosphates: } \\
\text { DDVP } \\
\text { Methamidophos } \\
\text { Omethoate } \\
\text { Others }\end{array}$ & $\begin{array}{r}980 \\
318 \\
157 \\
95 \\
45 \\
21\end{array}$ & $\begin{array}{l}379 \\
- \\
-\end{array}$ & 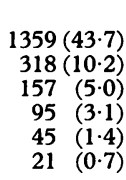 \\
\hline $\begin{array}{l}\text { Fenvalerate: } \\
\text { Pure EC } \\
\text { Mixed with organophosphates: } \\
\text { DDVP } \\
\text { Methamidophos } \\
\text { Omethoate } \\
\text { Others }\end{array}$ & $\begin{array}{r}492 \\
203 \\
123 \\
43 \\
30 \\
7\end{array}$ & $\begin{array}{l}729 \\
- \\
-\end{array}$ & $\begin{array}{rr}1221 & (39.2) \\
203 & (6.5) \\
123 & (3.9) \\
43 & (1.4) \\
30 & (1.0) \\
7 & (0.2)\end{array}$ \\
\hline $\begin{array}{l}\text { Cypermethrin: } \\
\text { Pure EC } \\
\text { Mixed with organophosphates: } \\
\text { Methamidophos }\end{array}$ & 7 & - & $\begin{array}{l}8(0 \cdot 2) \\
4(0 \cdot 1)\end{array}$ \\
\hline Total & 2004 & 1109 & 3113 \\
\hline
\end{tabular}

sweating on the forehead or all over, and $68 \%$ of them wiped off their sweat with hands or sleeves, which were usually, therefore, contaminated with pyrethroids and led to secondary dermal exposure.

\section{Pyrethroid exposure}

Pesticides-Exposure to major types of pyrethroids including $2.5 \%$ deltamethrin EC (Roussel-Uclaf Company), $20 \%$ fenvalerate EC (Suimoto Company) and $10 \%$ cypermethrin EC (Shell Oil Company) accounted for exposure in $2588(83 \cdot 1 \%)$ subjects, whereas $16.9 \%$ of the spraymen were exposed to pyrethroids mixed with organophosphates-that is, DDVP $(9 \cdot 0 \%)$, methamidophos $(4 \cdot 6 \%)$, omethoate $(2 \cdot 4 \%)$, or others $(0.9 \%)$ (table 1$)$.

Types of sprayers-Four types of sprayers were used by the cotton farmers-namely, (1) single nozzle pressure type $(83 \%)$; (2) bearing and mobile type (16\%); (3) mechanical type; (4) ultralow volume type. During spraying, the leakage or stoppage of sprayers occurred with $778(25.0 \%)$ subjects; $65 \%$ of them cleared the stoppage using their mouth or hands. The preparation of pyrethroids was done by hand by $91.6 \%$ of the cotton farmers, who used the lid of the pyrethroid container instead of a measuring glass. These factors led to skin contamination with pyrethroid on the hands in $92 \%$ of the 2004 spraymen studied in 1987.

Use of pyrethroids-Most $(95 \cdot 1 \%)$ of the pyrethroids were prepared with a dilution of less than 1:4000 before use. The highest concentration was 1:50 for use in the ultralow volume type of sprayer. Pyrethroids mixed with organophosphates were used at ratios of $1: 1$ or $1: 2$ by $74.6 \%$ of the spraymen. The spraying time was less than four hours in $69 \cdot 1 \%$ of the spraymen, and $3.8 \%$ of all the subjects had sprayed consecutively for only two or three days. The amount of pyrethroid EC sprayed was less than a total of $40 \mathrm{ml}$ for most of the spraymen $(68 \cdot 4 \%)$. A survey on the knowledge, attitude, and practise (KAP) of pyrethroid use was carried out during the survey.

\section{Concentration of pyrethroids in air and urine}

To define the quantity of the absorbed pyrethroids resulting from exposure through inhalation or dermal exposure during spraying, 38 spraymen were selected as subjects for monitoring. All the samples were analysed by gas chromatography. ${ }^{3}$

Environmental monitoring-Determination of air concentrations of pyrethroids in the breathing zone was done for one day spraying in 1987 and three day spraying in 1988 . The results were $0.01-0.89 \mu \mathrm{g} / \mathrm{m}^{3}$ for deltamethrin and $0.06-1.98 \mu \mathrm{g} / \mathrm{m}^{3}$ for fenvalerate. The highest respiratory exposure (air concentration at the breathing zone $x$ ventilatory volume for light physical labour $(10 \mathrm{l} / \mathrm{h})$ ) was $0.53 \mu \mathrm{g} / \mathrm{h}$ for deltamethrin and $1 \cdot 19 \mu \mathrm{g} / \mathrm{h}$ for fenvalerate.

Assessment of dermal exposure-Gauze pads were applied on clothes and skin according to the standardised method reported previously. ${ }^{2}$ Pyrethroids were detectable in $95.1 \%$ of the samples (143 gauze pads). Based on the height, body weight, and surface area of each person, the cumulative content of pyrethroids on bare skin was estimated to be 0.02 $1.56 \mathrm{mg} / \mathrm{h}$ for deltamethrin and $1.25-6.42 \mathrm{mg} / \mathrm{h}$ for fenvalerate.

Biological monitoring-Urine samples were collected from each of 18 subjects at pre-exposure, and at $3,6,9,12,24,48$, and 72 hours after the beginning of the one day spraying. The highest content of deltamethrin detected by gas chromatography in urine from six subjects of the deltamethrin group was $0.3 \mu \mathrm{g} / 1$ and in the group exposed to deltamethrin organophosphate mixture (six subjects) it was 0.4 $\mu \mathrm{g} / \mathrm{l}$. The highest urinary concentration of fenvalerate was $0.33 \mu \mathrm{g} / 1$ (six fenvalerate spraymen). Deltamethrin in urine disappeared within 12 hours and the fenvalerate within 24 hours after the beginning of spraying. The deltamethrin metabolite $\mathrm{Br} 2 \mathrm{~A}$, in urine, was detectable by high pressure liquid chromatography in nine of 12 spraymen and ranged from 9-140 $\mu \mathrm{g} / 1 .{ }^{4}$ This was much higher than the original deltamethrin excreted in urine.

\section{DIAGNOSTIC CRITERIA OF ACUTE PYRETHROID POISONING}

The diagnosis of mild acute pyrethroid poisoning was made in those with verified exposure to pyrethroids if they had abnormal facial sensations, and significant systemic symptoms (dizziness, headache, fatigue, nausea, and loss of appetite) and signs 
Table 2 Symptoms and signs of 834 spraymen clinically affected by pyrethroids

\begin{tabular}{|c|c|c|c|c|c|}
\hline Symptoms & $\begin{array}{l}\text { No of } \\
\text { persons (\%) }\end{array}$ & Symptoms & $\begin{array}{l}\text { No of } \\
\text { persons (\%) }\end{array}$ & Signs & $\begin{array}{l}\text { No of } \\
\text { persons }(\%)\end{array}$ \\
\hline $\begin{array}{l}\text { Abnormal sensations } \\
\text { Dizziness } \\
\text { Headache } \\
\text { Fatigue } \\
\text { Nausea }\end{array}$ & $\begin{array}{r}768(92 \cdot 1) \\
121(14.5) \\
99(11.9) \\
91(10.9) \\
68(8 \cdot 2)\end{array}$ & $\begin{array}{l}\text { Loss of appetite } \\
\text { General malaise } \\
\text { Blurred vision } \\
\text { Chest tightness }\end{array}$ & $\begin{array}{l}44(5 \cdot 3) \\
33(4 \cdot 0) \\
23(2 \cdot 8) \\
18(2 \cdot 2)\end{array}$ & $\begin{array}{l}\text { Listlessness } \\
\text { Skin papules } \\
\text { Muscular fasciculation } \\
\text { Others }\end{array}$ & $\begin{array}{r}10(1 \cdot 2) \\
1(0 \cdot 1) \\
1(0 \cdot 1) \\
25(3 \cdot 0)\end{array}$ \\
\hline
\end{tabular}

(listlessness and muscular fasciculation) leading to absence for more than one day, and reasonable exclusion of other possible diseases. ${ }^{1}$ In those who sprayed pyrethroids mixed with organophosphates, their blood cholinesterase activity was measured for differential diagnosis. ${ }^{3}$

\section{STATISTICAL ANALYSIS}

All data were edited, coded, and fed to an IBM-PC/ AT computer for statistical analyses that included (1) prevalence of the related symptoms and of acute pyrethroid poisoning in cotton farmers in 1987 and 1988; (2) stratified analysis according to various simple factors (sex, age, kind of pyrethroids, mixed pesticides etc); and (3) analyses for causal factors.

\section{EFFECTS OF PYRETHROIDS ON COTTON FARMERS \\ Current effects}

In the spraymen studied, $3051(98 \%)$ were well before spraying pyrethroids and $834(26.9 \%)$ of the subjects developed various symptoms after spraying. Of these, 696 sprayed pure pyrethroids, and 138 sprayed pyrethroid organophosphate mixtures, and $768(92 \cdot 1 \%)$ complained of abnormal facial sensations, mainly burning and tingling which emerged as initial symptoms in $88.6 \%$ of them. These symptoms usually developed within four hours after the beginning of spraying and readily disappeared within 24 hours (table 2). Systemic symptoms (dizziness, headache, fatigue, nausea, and loss of appetite) were more frequently seen, but were minimal. Only 10

Table 3 Effects of pyrethroids on 3113 spraymen

\begin{tabular}{|c|c|}
\hline Effect of pyrethroids & $\begin{array}{l}\text { No of } \\
\text { persons }(\%)\end{array}$ \\
\hline $\begin{array}{l}\text { Pure pyrethroids } \\
\text { Total } \\
\text { With related symptoms } \\
\text { Mild acute poisoning }{ }^{\star}\end{array}$ & $\begin{array}{r}2588 \\
696(26 \cdot 88) \\
8(0.31)\end{array}$ \\
\hline $\begin{array}{l}\text { Pyrethroids-organophosph } \\
\text { Total } \\
\text { With related symptoms } \\
\text { Mild acute poisoning }{ }^{\dagger}\end{array}$ & $\begin{array}{l}525 \\
138(26 \cdot 28) \\
2(0 \cdot 38)\end{array}$ \\
\hline Total & 3113 \\
\hline
\end{tabular}

spraymen who developed significant systemic symptoms and showed listlessness or muscular fasciculation were diagnosed as having mild acute pyrethroid poisoning (table 3). These comprised four cases of acute deltamethrin poisoning, four of acute fenvalerate poisoning, and two cases induced by deltamethrin DDVP mixture (the subjects had normal blood cholinesterase activity). They all recovered within two to four days. In this study, the prevalence of occupational acute pyrethroid poisoning was $0.31 \%$ in subjects exposed to pyrethroids and $0.38 \%$ in cotton growers exposed to pyrethroid and organophosphate mixtures.

\section{Effects of previous exposure to pyrethroid}

There were 2131 cotton growers in this study who had been exposed to pyrethroids previously between 1982-8. Among them, 696 spraymen had related symptoms in this survey and $58.8 \%$ of them were found to have had similar symptoms during previous exposures; they had all recovered satisfactorily in two days without any sequelae. In the rest of the 1435 spraymen without any symptoms in this study, only $9.5 \%$ of them had had symptoms during previous exposure. The difference between the two groups was significant $(p<0.01)$.

\section{CAUSAL FACTORS}

The survey on the knowledge, attitude, and practise of pyrethroid use showed that $2173(69.8 \%)$ subjects were not aware of the toxicity of pyrethroids. Their personal protection was not satisfactory. None of the spraymen wore masks or gloves and most of them kept their upper extremities bare and wore only sandals during spraying. Moreover, most of the spraying operation did not comply with safe handling, which requires spraying every other row of cotton plants, going backwards or against the wind during spraying, and avoiding eating or smoking in the field. As a consequence, contamination of pyrethroids on shoes and trousers happened in $93.1 \%$ and $65 \%$ of the spraymen. The area of dermal contamination of pyrethroids for the spraymen, was, however, less than $30 \%$ of their body surface. ${ }^{3}$ The results also showed that related symptoms appeared more frequently in young men and in those with longer spraying durations and more pyrethroid use in the field. Moreover, the spraymen using sprayers 
Table 4 Causal factors related to occurrence of symptoms in spraymen

\begin{tabular}{|c|c|c|c|c|}
\hline \multirow[b]{2}{*}{ Causal factors } & \multicolumn{2}{|c|}{ Symptoms } & \multirow{2}{*}{$\begin{array}{l}\text { Positive } \\
\text { rate } \\
(\%)\end{array}$} & \multirow[b]{2}{*}{ p Value } \\
\hline & Yes & No & & \\
\hline \multicolumn{5}{|l|}{ Sex: } \\
\hline Men & 510 & 1720 & $22 \cdot 9$ & \\
\hline Women & 324 & 559 & $36 \cdot 7$ & $<0.001$ \\
\hline \multicolumn{5}{|l|}{ Age: } \\
\hline$<25$ & 287 & 654 & 30.5 & \\
\hline $\begin{array}{l}25- \\
45-\end{array}$ & 479 & 1309 & $26 \cdot 8$ & \\
\hline & 316 & $17 \cdot 7$ & \\
\hline $\begin{array}{l}\text { Spraying duration (day } \\
1 \\
2-3\end{array}$ & $\begin{array}{r}761 \\
73\end{array}$ & 2231 & $25 \cdot 4$ & \\
\hline \multicolumn{5}{|l|}{$\begin{array}{l}\text { Use of pyrethroid EC } \\
\text { (ml/person): }\end{array}$} \\
\hline $\begin{array}{l}<20 \\
20-\end{array}$ & $\begin{array}{l}217 \\
311\end{array}$ & $\begin{array}{l}789 \\
813\end{array}$ & $\begin{array}{l}21 \cdot 6 \\
27 \cdot 7\end{array}$ & \\
\hline 40 & 143 & 317 & $31 \cdot 1$ & \\
\hline$\geqslant 60$ & 163 & 360 & $31 \cdot 2$ & $<0.001$ \\
\hline \multicolumn{5}{|l|}{$\begin{array}{l}\text { Use of pyrethroid EC } \\
\mathrm{ml} / \mathrm{M} \mu):^{\star}\end{array}$} \\
\hline$<20$ & 181 & 627 & $22 \cdot 4$ & \\
\hline $\begin{array}{l}20- \\
\geqslant 40\end{array}$ & $\begin{array}{l}346 \\
307\end{array}$ & $\begin{array}{l}879 \\
773\end{array}$ & $\begin{array}{l}28 \cdot 2 \\
28 \cdot 4\end{array}$ & $<0.005$ \\
\hline \multirow{2}{*}{\multicolumn{5}{|c|}{$\begin{array}{l}\text { Contamination of clothing: } \\
(n=2775)\end{array}$}} \\
\hline & & & & \\
\hline $\begin{array}{l}\text { None } \\
\text { Jacket }\end{array}$ & $\begin{array}{l}171 \\
159\end{array}$ & 491 & $\begin{array}{l}25 \cdot 8 \\
32 \cdot 4\end{array}$ & \\
\hline Trousers & $\begin{array}{l}159 \\
438\end{array}$ & $\begin{array}{r}332 \\
1161\end{array}$ & $\begin{array}{l}32 \cdot 4 \\
27 \cdot 4\end{array}$ & \\
\hline Jacket and trousers & 12 & 11 & $52 \cdot 2$ & $<0.005$ \\
\hline \multicolumn{5}{|l|}{ Dilution of pyrethroid: } \\
\hline$<1000$ & 10 & 24 & $29 \cdot 4$ & \\
\hline $1000-$ & 318 & 822 & $27 \cdot 9$ & \\
\hline $2000-$ & 473 & 1314 & $26 \cdot 5$ & \\
\hline$\geqslant 4000$ & 33 & 119 & $21 \cdot 7$ & $<0.001$ \\
\hline \multicolumn{5}{|l|}{$\begin{array}{l}\text { Leakage or stoppage of } \\
\text { sprayer: }\end{array}$} \\
\hline Yes & 268 & 510 & $34 \cdot 4$ & \\
\hline No & 566 & 1769 & $24 \cdot 2$ & $<0.001$ \\
\hline
\end{tabular}

$\star_{1} \mathrm{M} \mu=0.0677$ hectares.

with leakage or stoppage during operating had more frequent related symptoms. Significant statistical differences were found between the compared groups (table 4).

\section{Discussion}

The results of our epidemiological study show that 834 subjects among 3113 spraymen surveyed were clinically affected by exposure to pyrethroids, accounting for $26.8 \%$ in the subjects exposed to pure pyrethroid and $26.3 \%$ in spraymen with pyrethroidorganophosphate exposures. The effects pyrethroids mainly induced were abnormal facial sensations that are thought to be specific manifestations of increased excitability of sensory nerve endings in the face ${ }^{5}$ and that disappear within 24 hours. Systemic symptoms including dizziness, headache, fatigue, nausea, loss of appetite, and listlessness resulting from pyrethroid exposure indicate an effect on the nervous system. This was generally mild in exposed subjects. These findings accord with the diagnostic criteria of acute pyrethroid poisoning used in our epidemiological study.

Among 3113 spraymen, only 10 of them developed significant systemic symptoms as well as abnormal facial sensations to be diagnosed as having mild occupational acute pyrethroid poisoning (a prevalence of $0.31 \%$ in subjects exposed to pure pyrethroid and $0.38 \%$ in subjects with pyrethroid organophosphate exposures). The toxicity of pyrethroids in mammals is lower than that of organophosphates. ${ }^{6}$ The prevalence of acute pyrethroid poisoning in cotton farmers found in this study is also lower than the prevalence of acute organophosphate poisoning in the cotton areas of China (reported to be from $0 \cdot 16 \%$ to $11 \%$ ). ${ }^{7}$ On the other hand, organophosphates can inhibit the degradation of pyrethroids and consequently increase their toxicity. ${ }^{8}$ No significant difference in the prevalences of acute poisoning was found, however, between the pure pyrethroid group and the pyrethroid organophosphate mixture group in our study.

Synthetic pyrethroids are metabolised and excreted rapidly. ${ }^{3}$ Their chronic toxicity in man has not been well documented. The retrospective survey done in this study on 2131 cotton growers who had had previous exposures to pyrethroids showed no evidence of longstanding effects. This result indicates that pyrethroids are unlikely to have chronic toxicity in man. The significant difference in the frequency of related symptoms during previous exposure to pyrethroids between groups with and without symptoms in our present study might indicate differences in the two groups either in susceptibility to pyrethroids or in the attitude to taking precautions during spraying.

Several causal factors are related to the occurrence of acute pyrethroid poisoning. Our results indicate that sloppy handling during spraying that leads to heavy skin contamination with pyrethroids is the most important reason for acute intoxication in spraymen (table 4), because the air concentration of deltamethrin at the breathing zone in cotton spraymen was much lower but the urinary excretion rate was higher than that in subjects engaged in dividing and packaging deltamethrin. ${ }^{9}$ Therefore, dermal contamination of pyrethroids seems to be of greater importance to the cotton farmer than air contamination and the minimisation of dermal exposure during spraying should be the priority in the prevention of acute pyrethroid poisoning in cotton farmers. In the meantime, the strategies of education for improving the knowledge, attitude, and practice of pyrethroid use by cotton farmers as well as the promulgation of regulations and precautionary guidelines for safe handling of pesticides are obviously important and necessary. 
This work was carried out with the aid of a grant from the International Development Research Centre, Ottawa, Canada. We are grateful to our colleagues at Hebei Institute of Occupational Health, as well as the Sanitation and Antiepidemic Station of Shijiazhuang Prefecture and Goacheng county for their assistance in this study.

Requests for reprints to: Professor Fengsheng He, Institute of Occupational Medicine, Chinese Academy of Preventive Medicine, 29 Nan Wei Road, Beijing 100050, People's Republic of China.

1 He F, Wang S, Liu L, Chen S, Zhang Z, Sun J. Clinical manifestations and diagnosis of acute pyrethroid poisoning. Arch Toxical 1989;63:54-8.

2 World Health Organisation. Pesticide Development and Safe Use Unit, Division of Vector Biology Control. Field surveys of exposure to pesticides standard protocol $V B C / 82$. Geneva: WHO, 1982.

3 Zhang Z, Yao P, Sun J, Chen S, Li Q, He F. Exposure levels and biological monitoring of pyrethroids in spraymen. $\mathrm{Br} J$ Ind Med (in press).

4 Yao P, Li Y, Zhang Z, He F. Biological monitoring of deltamethrin metabolites in spraymen urine. Chinese Journal of Hygiene Research 1989;6:1-4.

5 Le Quesne PM, Maxwell IC. Transient facial sensory symptoms following exposure to synthetic pyrethroids: a clinical and electrophysiological assessment. Neurotoxicology 1980;2: 1-11.

6 Roussel Uclaf. Deltamethrin monograph. Paris: Roussel Uclaf; 1982.

7 Shih J, Wu Z, Wang Y, Xue S, Gu X. Prevention of acute parathion and demeton poisoning in farmers around Shanghai. Scand J Work Environ Health 1985;11:49-54.

8 Houston DH. The metabolic fate of synthetic pyrethroid insecticides in mammals. In: Bridges JW, et al, eds. Progress in drug metabolism. Chichester: John Wiley \& Sons, 1979: 224-55.

9 He F, Sun J, Han K, Wu Y, Yao P, Wang S, Liu L. Effects of pyrethroids insecticides on subjects engaged in packaging pyrethroids. Br J Ind Med 1988;45:548-51.

Accepted 20 August 1990 